\title{
Ocena mikrostruktury napoiny ze srebra na tytanie
}

\author{
Microstructure of Ag on the Ti plate padding weld
}

\section{Streszczenie}

W pracy podjęto próbę oceny mikrostruktury napoiny wykonanej z drutu srebrnego na blachach tytanowych. Ocenę przeprowadzono z wykorzystaniem mikroskopii świetlnej i skaningowej mikroskopii elektronowej. Ujawnione wyniki obserwacji wskazują na występowanie złożonej struktury płytkowej w obszarze materiału rodzimego (tytanu) i budowę dendrytyczną w napoinie.

Słowa kluczowe: fazy międzymetaliczne; napawanie; tytan; srebro; TIG

\section{Abstract}

The microstructure of $\mathrm{Ag}$ on $\mathrm{Ti}$ plate padding weld was investigated in the paper. The evaluation was carried out using light microscopy and scanning electron microscopy. Observation results indicate the presence of a complex lamellar structure in the area of the native material (titanium) and dendritic structure in the clad.

Keywords: intermetallic phase; clading, titanium; silver; TIG

\section{Wstęp}

Spawanie tytanu i jego stopów zaliczane jest do procesów trudnych $w$ realizacji i wymaga stosowania specyficznych zabiegów. Wynika to w znacznej mierze z wysokiego powinowactwa tytanu w podwyższonej temperaturze (powyżej $350{ }^{\circ} \mathrm{C}$ ) do takich pierwiastków jak tlen, azot, wodór i węgiel. Ochronę nagrzanego metalu zapewnia się przez stosowanie atmosfery ochronnej i zachowanie czystości spawanych elementów [1]. Mała wartość współczynnika przewodnictwa cieplnego tytanu sprawia, że spoina oraz strefa wpływu ciepła (SWC) jest przez długi czas w zakresie temperatur, w których dochodzi do absorpcji gazów atmosferycznych i ich dyfuzji do materiału. Obecność zanieczyszczeń w wysokiej temperaturze sprzyja rozrostowi ziaren oraz tworzeniu się fazy $\beta-\mathrm{Ti}[1 \div 4]$.

Stopy a-Ti cechują się dobrą spawalnością i wykazują małą wrażliwość na zmiany warunków spawania. Istotną rolę w przypadku własności plastycznych odgrywa szybkość chłodzenia spoiny oraz SWC. Jeżeli materiał poddany spawaniu jest w stanie po obróbce plastycznej to istotny jest czas przebywania w zakresie temperatury rekrystalizacji. Dla uzyskania najkorzystniejszych własności mechanicznych stopów jednofazowych a-Ti stosuje się wyżarzanie powyżej temperatury rekrystalizacji, a następnie chłodzenie w powietrzu [5].

Stopy $\beta$-Ti są plastyczne, ale charakteryzują się małą stabilnością cieplną oraz skłonnością do mikrosegregacji składu chemicznego, szczególnie w zakresie mikrododatków stopowych stabilizujących fazę $\beta$. Ogranicza to spawalność tej grupy stopów tytanu. Dwufazowe stopy tytanu $a+\beta$ do zawartości $20 \%$ fazy $\beta$ są dobrze spawalne [3]. W porównaniu ze stopami a stopy $\alpha+\beta$ wykazują skłonność do tworzenia struktury typu martenzytycznego $\left(a^{\prime}\right)$, która ogranicza ich plastyczność. Efekt utraty plastyczności można zaobserwować w stopach zawierających ponad 3\% pierwiastków stabilizujących fazę $\beta$ (np. Mo, V itp.) poddawanych po spawaniu obróbce cieplnej. Stopy o zawartości poniżej 3\% pierwiastków stabilizujących fazę $\beta$ mają ogólnie dobre własności plastyczne [6].

$\mathrm{Na}$ budowę krystaliczną spoiny oraz SWC oddziałuje skład chemiczny stopu, zawartość zanieczyszczeń, własności fizyczne, zachodzące przemiany fazowe oraz parametry cyklu cieplnego wybranej metody spawania $[1,7]$. Uzyskana jakość połączeń spawanych stopu tytanu zależy od zastosowanego cyklu cieplnego. Z uwagi na niski współczynnik przewodnictwa cieplnego, wysoka temperatura materiału utrzymuje się dwukrotnie dłużej niż w stali niestopowej. Powoduje to rozrost ziaren fazy $\beta$ powstałych podczas przemiany alotropowej, co niekorzystnie wpływa na własności wytrzymałościowe materiału $[1,8 \div 9]$.

Problemem podczas wytwarzania złączy różnorodnych jest ich wysoka skłonność do pęknięć gorących, wskutek występowania twardych i kruchych faz międzymetalicznych i wysokich naprężeń spawalniczych wywołanych skurczem spoiny. W przypadku połączenia metodami spawania łukowego stali niestopowej z tytanem, powstaje struktura zbudowana $z$ twardych i kruchych faz międzymetalicznych jak TiFe i TiFe 2 . Fazy te wpływają niekorzystnie na własności plastyczne. Dla ograniczenia tego efektu stosowane są

Mgr inż. Marcin Ptasiński, dr inż. Lechosław Tuz - AGH Akademia Górniczo-Hutnicza.

Autor korespondencyjny/Corresponding author. ptamar@agh.edu.pl 
warstwy buforowe z materiałów wykazujących dobrą rozpuszczalność składników tworzących spoinę o wysokiej plastyczności $[1,5]$.

Wśród typowych materiałów na warstwy buforowe najczęściej wykorzystuje się nikiel i jego stopy umacniane roztworowo, lecz ze względu na dodatek żelaza i innych pierwiastków w stopach niklu nie jest on najkorzystniejszym rozwiązaniem i może powodować występowanie makroi mikropęknięć. Innymi pierwiastkami korzystnymi z punktu widzenia spawalności są srebro i niob. Jak wynika z układu równowagi $\mathrm{Ag}-\mathrm{Ti}$ (rys. 1), dodatek do $2 \%$ at. Ag stabilizuje występowanie fazy a. Wraz ze wzrostem stężenia srebra do zawartości ok. 33\% występuje mieszanina a-Ti+AgTi ${ }_{2}$. Związek międzymetaliczny $\mathrm{AgTi}_{2}$ powstaje $\mathrm{z} \beta$-Ti+AgTi przy stężeniu $33 \%$ at. Ag w wyniku przemiany perytektoidalnej podczas chłodzenia z temperatury $945{ }^{\circ} \mathrm{C}$. W zakresie stężenia $48 \div 50 \%$ at. Ag występuje związek międzymetaliczny AgTi, a od 50 do $100 \%$ at. Ag stop jest mieszaniną roztworu

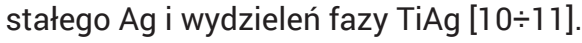

W celu oceny mikrostruktury powstającej na skutek procesów spawalniczych przeprowadzono próbę napawania blachy tytanowej Grade 1 drutem srebrnym. Dla osiągnięcia efektu wysokiego wymieszania stosowano wysokie parametry prądowe.

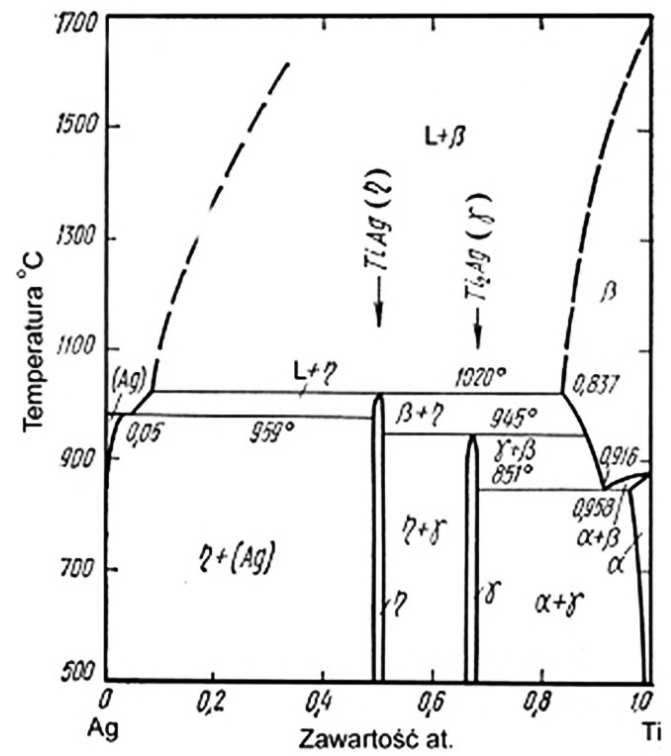

Rys. 1. Układ równowagi fazowej Ag-Ti [11]

Fig. 1. Ag-Ti phase diagram [11]

\section{Badania własne}

Do badań wykorzystano blachę z tytanu w gatunku 1 (Grade 1) o składzie chemicznym wg ASTM B348 wskazanym w tablicy I. Wykorzystania do napawania blacha miała następujące wymiary $100 \times 100$ mm i grubość $5 \mathrm{~mm}$. Proces napawania prowadzono ręcznie elektrodą nietopliwą w osłonie gazowej (TIG - 141 wg EN ISO 4063). Jako materiał dodatkowy wykorzystano srebrny drut lity o średnicy $2,5 \mathrm{~mm}$ i czystości 99,9\% wag. Jako gaz osłonowy stosowano argon 5.0 z natężeniem wypływu $16 \mathrm{l} / \mathrm{min}$. Proces napawania prowadzono $z$ natężeniem prądu $120 \mathrm{~A}$.

Próbki do badań zostały wycięte prostopadle do osi napoiny za pomocą piły tarczowej, tak aby obejmowały materiał rodzimy, SWC i napoinę, a następnie zainkludowane. Szlifowanie przeprowadzono z wykorzystaniem wodnych papierów ściernych o rosnącej gradacji od 100 do 4000 . Polerowanie końcowe wykonano na suknie polerskim zwilżonym zawiesiną $\mathrm{Al}_{2} \mathrm{O}_{3}$ na polerce automatycznej. Proces trawienia
Tablica I. Skład chemiczny tytanu Grade 1; max. \% wag. (ASTM B348) Table I. Chemical composition of titanium Grade 1, max wt.\% (ASTM B348)

\begin{tabular}{|c|c|c|c|c|c|}
\hline Fe & $\mathbf{C}$ & $\mathbf{N}$ & $\mathbf{0}$ & $\mathbf{H}$ & $\mathrm{Ti}$ \\
\hline 0,2 & 0,08 & 0,03 & 0,18 & 0,015 & reszta \\
\hline
\end{tabular}

został przeprowadzony dwuetapowo, najpierw użyto wodnego roztworu kwasu fluorowego, a następnie alkoholowego roztworu kwasu fluorowego i kwasu azotowego.

Tak przygotowane zgłady poddano obserwacjom przy wykorzystaniu mikroskopii świetlnej i skaningowej mikroskopii elektronowej. Wykonane obserwacje nie wykazały występowania nieciągłości materiałowych w obszarze napawanym w postaci pęknięć, mikropęknięć, pustek gazowych itp.

Obserwacje blachy tytanowej (rys. 2) ujawniły płytkową strukturę charakterystyczną dla stopu a-Ti o wysokiej czystości, nagrzanego w zakresie fazy $\beta$-Ti, a następnie chłodzonego na powietrzu. Powstała struktura zbudowana jest z płytek fazy a-Ti z niewielką ilością fazy $\beta$-Ti. Ułożenie płytek w tak zwany "splot koszyczkowy" (ang. basket weave), zapewnia korzystne właściwości mechaniczne i plastyczne, a jednocześnie występowanie tej struktury wynika z zanieczyszczenia tytanu m.in. wodorem [3].

Mikrostruktura napoiny wykonana srebrem (99,9\% wag.) na blasze tytanowej przedstawiona jest na rysunku 3 . Napoina ma strukturę dendrytyczną z wyraźnie zarysowanymi szerokimi obszarami międzydendrytycznymi. W oparciu o analizę układu równowagi fazowej (rys. 1) należy przypuszczać, że pierwotnie z cieczy krystalizowały dendryty o składzie chemicznym bogatszym w tytan. Dalej podczas stygnięcia wystąpiła przemiana eutektoidalna, w wyniku której powstała mieszanina fazy a-Ti i fazy międzymetalicznej $\mathrm{AgTi}_{2}$. Ze względu na obecność pierwiastków międzywęzłowych w tytanie należy przypuszczać, że występują również drobne wydzielenia fazy $\beta$.
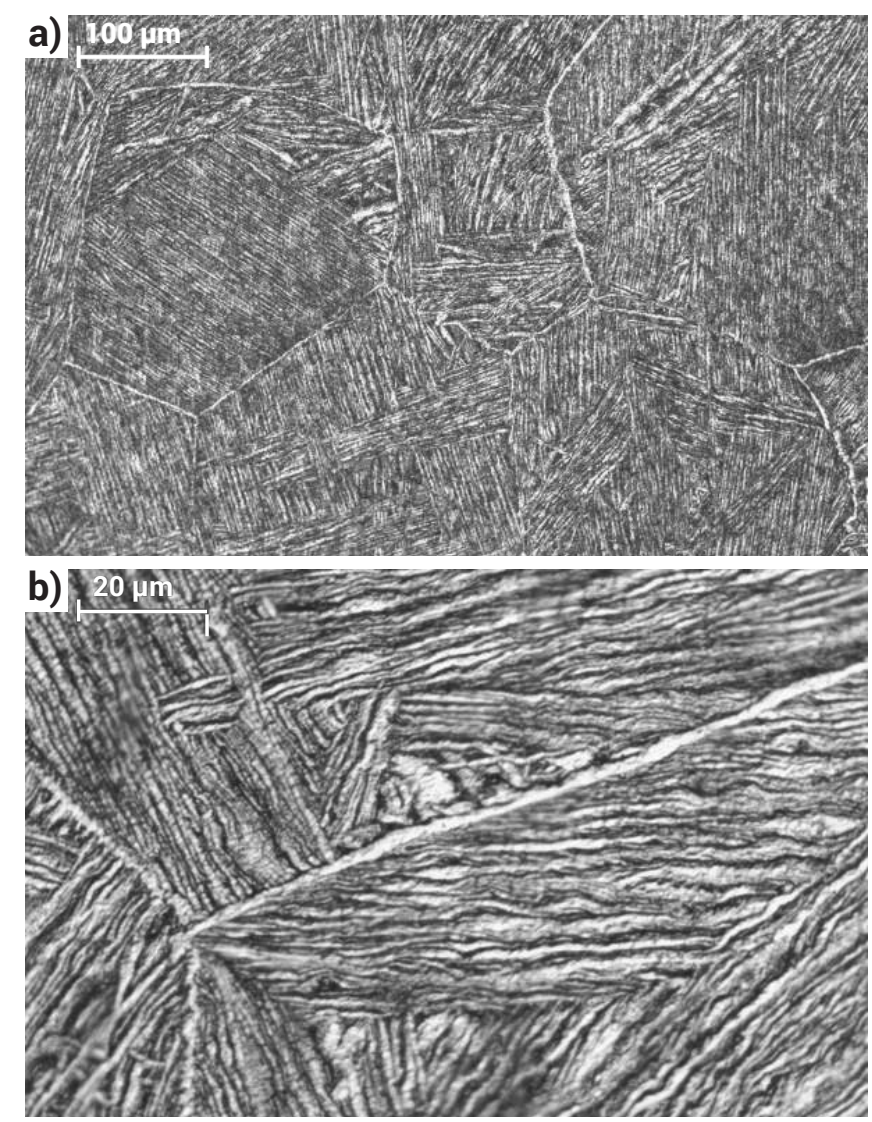

Rys. 2. Mikrostruktura tytanu, mikroskopia świetlna

Fig. 2. Titanium microstructure, light microscopy 

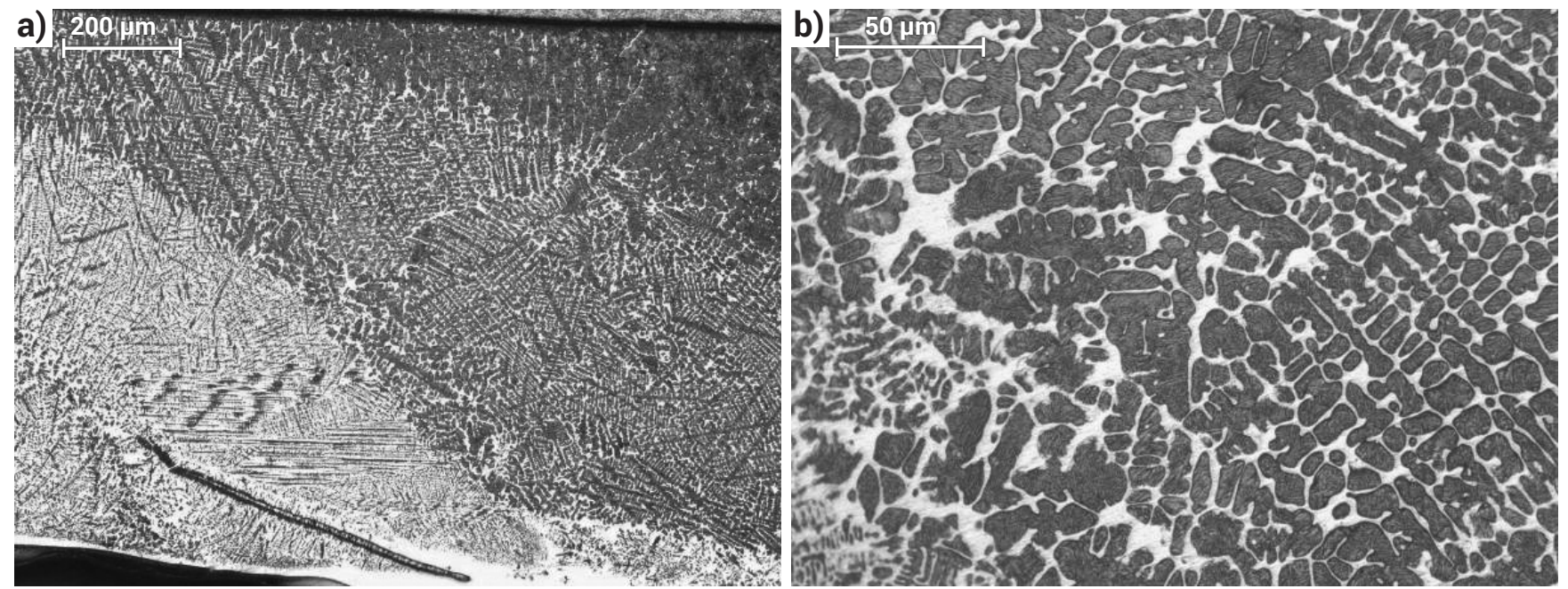

Rys. 3. Mikrostruktura napoiny, mikroskopia świetlna

Fig. 3. Padding weld microstructure, light microscopy

Obserwacja przy wykorzystaniu skaningowej mikroskopii elektronowej (rys. 4) ujawniła złożoną budowę rdzeni dendrytów, gdzie obserwowano fazę a-Ti w postaci płytek w układzie Widmanstatten'a. Wraz z oddalaniem się od linii wtopienia obserwowano odmienną morfologię struktury.

Tuż przy linii wtopienia występuje wąska strefa o budowie płytkowej, bez wyraźnych jasnych obszarów (rys. 5a). Wskazuje to, że jest to materiał podstawowy, który uległ nadtopieniu, ale nie następowało mieszanie $z$ materiałem dodatkowym. Wraz z oddalaniem się od linii wtopienia obserwowano strukturę dendrytyczną ze zwiększającym się udziałem jasnych obszarów (rys. 3a, rys. 5b).

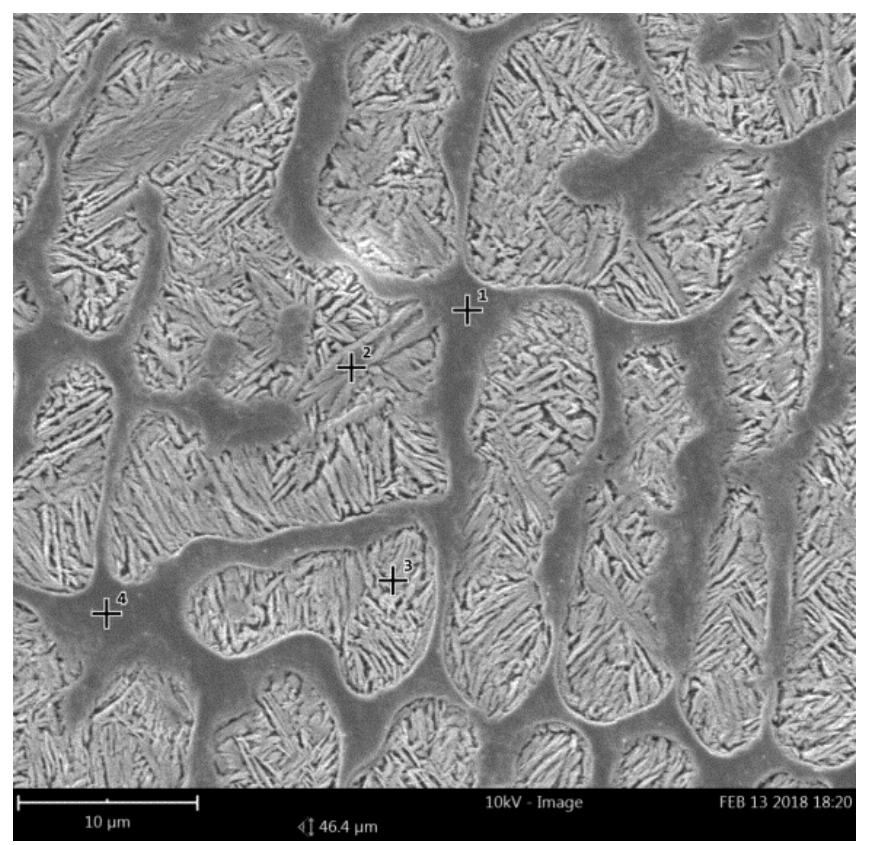

Rys. 4. Mikrostruktura napoiny, skaningowa mikroskopia elektronowa Fig. 4. Padding weld microstructure, SEM
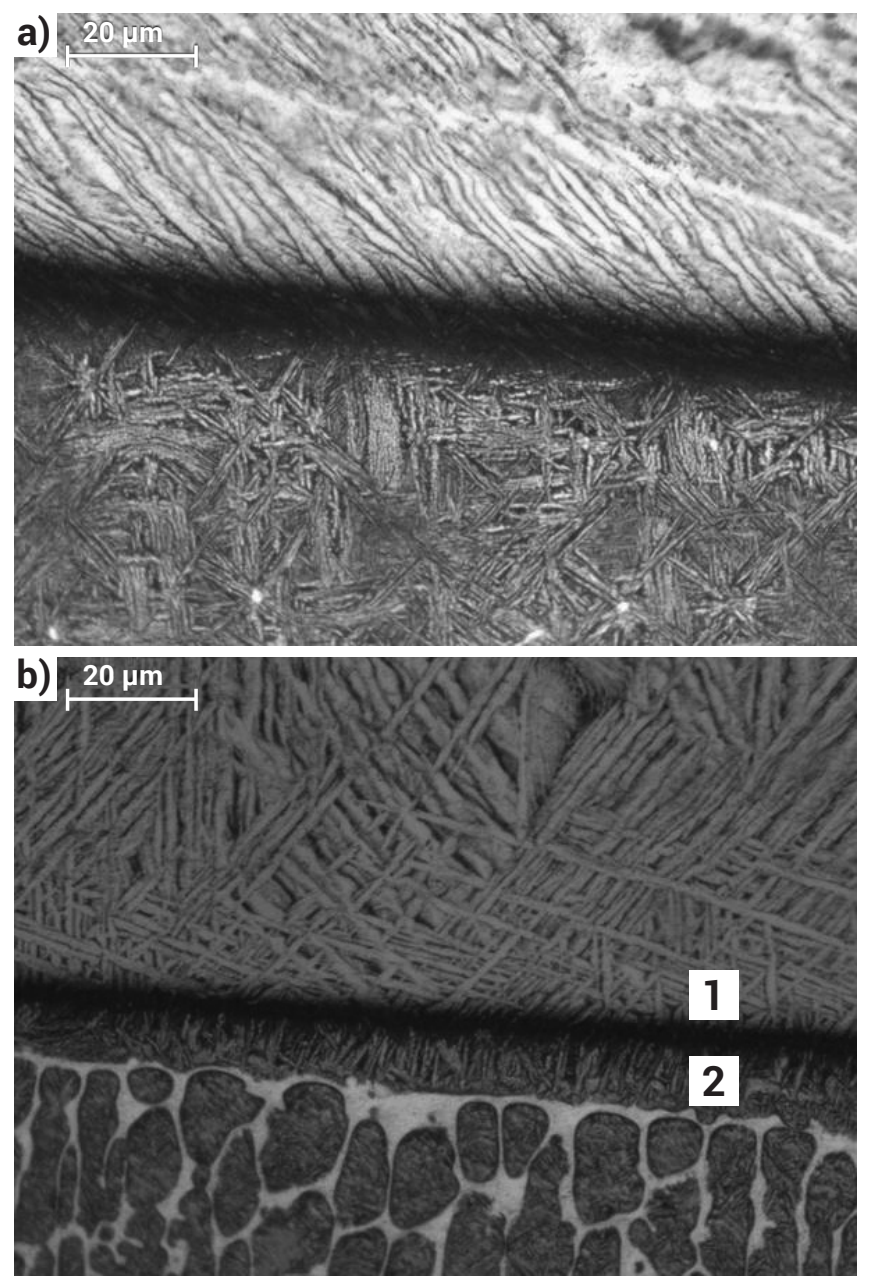

Rys. 5. Mikrostruktura w obszarze przy linii wtopienia: a) budowa płytkowa, b) budowa płytkowa (1) i budowa dendrytyczna napoiny (2) Fig. 5. Microstructure near to fusion line: a) lamellar structure, b) lamellar structure (1) and dendrites in the padding weld (2)

\section{Wnioski}

Na podstawie przeprowadzonych badań sformułowano następujące wnioski:

1. Możliwe jest uzyskanie napoin wykonanych drutem srebrnym na blachach z tytanu Grade 1 wolnych od pęknięć i innych nieciągłości.

2. Napoina ma strukturę dendrytyczną o płytkowej budowie rdzeni dendrytów, charakterystyczną dla stopów a-Ti po wolnym chłodzeniu.

3. Budowa płytkowa materiału rodzimego oraz napoiny wskazuje, że podczas procesu napawania mogło dojść do zanieczyszczenia nagrzanego metalu gazami z atmosfery, które mogły spowodować utworzenie struktury płytkowej (,,basket weave”). 


\section{Literatura}

[1] Lalik S., Niewielski G.: Badania złącz spawanych blach platerowanych tytanem Inżynieria Materiałowa, nr 5/2009.

[2] Mechow R., Tubielewicz K., Błaszczuk W.: Tytan i jego stopy gatunki właściwości, zastosowanie, technologia obróbki, degradacja, Politechnika Częstochowska, 2004.

[3] Polmear I.J.: Light Alloys Metalurgy of the light Metals, Third edition London, 1995.

[4] Dobrzański L.: Materiały inżynierskie i projektowanie materiałowe podstawy nauki o materiałach i metaloznawstwo Podstawy nauki o materiałach i metaloznawstwo, Wydawnictwo naukowo-Techniczne, Gliwice - Warszawa, 2006.

[5] Lutjering G., Williams J.C.: Titanium, Springer Verlag Berlin Heidelberg, 2003.

[6] Juszczyk B., Szkliniarz W.: Wpływ parametrów technologicznych na strukturę i właściwości dwufazowych stopów na osnowie fazy międzymetalicznej TiAl, Tytan i jego stopy VIII Ogólnopolska konferencja, Warszawa, 2005.
[7] Praca zbiorowa: Metallurgia i technologia svarki titana i jego splavov. Kiev: Naukowa Dumka 1986.

[8] Skrzypek S., Przybyłowicz K.: Inżynieria metali nieżelaznych, wydawnictwo AGH Kraków, 2012.

[9] Melechow R., Tubielewicz K., Błaszczuk W.: Tytan i jego stopy: gatunki, właściwości, zastosowanie, technologia obróbki, degradacja, Wyd. Politechnika Częstochowska, 2004.

[10] Szaraniec B., Gorczka T.: Structure and properies of Ti-Ag alloys produced by powder metallurgy, Journal of Alloys and Compounds 709, 2017, pp. 464-472

[11] Li M., Li Ch., Wang F., Zhang W.: Experimental study and thermodynamic assessment of the Ag-Ti system, Computer Coupling of Phase Diagrams and Thermochemistry 29, 2005, pp. 269-275 